\title{
The EAAT2 (GLT-1) gene in motor neuron disease: absence of mutations in amyotrophic lateral sclerosis and a point mutation in patients with hereditary spastic paraplegia
}

\author{
Thomas Meyer, Christoph Münch, Helge Völkel, Patrick Booms, Albert C Ludolph
}

\begin{abstract}
Objectives-To investigate if sequence alterations of the excitatory amino acid transporter gene EAAT2 (GLT-1) may be a contributory factor to the pathogenesis of motor system degeneration. EAAT2 serves as a candidate gene as its reduced expression was reported in patients with amyotrophic lateral sclerosis (ALS). Furthermore, neurolathyrism, a motor neuron disease clinically related to hereditary spastic paraplegia (HSP), has been associated with an exogenous excitotoxin.

Methods-Sequence alterations were screened for in the coding region of EAAT2 in 55 patients with ALS and one family with autosomal dominant HSP (AD-HSP).

Results-In ALS, no sequence alteration in the EAAT2 gene have been found. Interestingly, a heterozygous A79G mutation of the EAAT2 gene was detected in two of seven affected patients with ADHSP in the same kindred. The absence of cosegregation with the familial disease showed that the detected variant was not the cause of disease. The A79G sequence variant was not found in 55 patients with ALS or in 50 non-neurological controls. Conclusion-The allelic variant of the EAAT2 gene in conjunction with the primary gene defect may be a modifying factor for the highly variable AD-HSP phenotype.

(F Neurol Neurosurg Psychiatry 1998;65:594-596)
\end{abstract}

Keywords: glutamate transporter; amyotrophic lateral sclerosis; hereditary spastic paraplegia; sequence alteration

Glutamate is a potent neurotoxin and transporter mediated uptake serves to maintain extracellular glutamate concentrations below toxic concentrations. ${ }^{1}$ Glutamate transporters serve as candidate genes for motor system degeneration as a reduced expression of the excitatory amino acid transporter EAAT2 has been reported in amyotrophic lateral sclerosis (ALS). ${ }^{2}$ Furthermore, lathyrism, an exogen- ous motor neuron disease, has been associated with the excitotoxic properties of the neurotoxin 3-N-oxalyl-2,3-diaminopropanoic acid (ODAP), formerly known as $\beta-\mathrm{N}-$ oxalylamino-L-alanine (BOAA). ${ }^{3}$ This disease shows symptoms identical with hereditary spastic paraplegia (HSP) - a diverse group of motor system disorders which affect the corticospinal tract. ${ }^{4}$ Although loci for the most common autosomal dominant form of HSP have been identified on chromosomes 14q, 2p, and $15 \mathrm{q}$ the causative genes for the autosomal dominant (AD)-HSP are still unknown. ${ }^{5}$ Here we report a screening for sequence alterations of the EAAT2 gene in patients with ALS and one family with AD-HSP.

\section{Patients and methods}

SUBJECTS

Fifty five patients with the sporadic form of ALS referred to the Department of Neurology, Charité Hospital, Humboldt University, Berlin, were studied. The diagnosis of definite ALS was made using the El Escorial classification. ${ }^{6}$

Seven patients and one non-affected person from one family with AD-HSP were also included in this study (fig 1). The age of onset ranged from one to 17 years with a mean age of onset of 6 years.

Fifty non-neurological control DNA samples obtained from volunteers with myocardial infarction were provided by the Department of Internal Medicine, Humboldt University, Berlin. Informed consent was obtained from each of the patients and controls.

POLYMERASE CHAIN REACTION CONDITIONS

Primers were designed for intronic sequences adjacent to the exon-intron border of each of the 10 protein coding exons of the EAAT2 gene as described previously. ${ }^{7}$ Polymerase chain reaction (PCR) amplifications were carried out in a total volume of $25 \mu \mathrm{l}$ containing $100 \mathrm{ng}$ genomic DNA, $80 \mathrm{ng}$ of each primer, $150 \mu \mathrm{M}$ dNTP, $60 \mathrm{mM}$ Tris $\mathrm{HCl}(\mathrm{pH} 10.0), 15$ $\mathrm{mM}\left(\mathrm{NH}_{4}\right)_{2} \mathrm{SO}_{4}$, and $1 \mathrm{U}$ Taq DNA polymerase (Boehringer Mannheim). Samples were denatured for 4 minutes at $94^{\circ} \mathrm{C}$ and passed through 30 cycles of amplification, consisting and in revised form

26 January 1998

Accepted 19 March 1998 


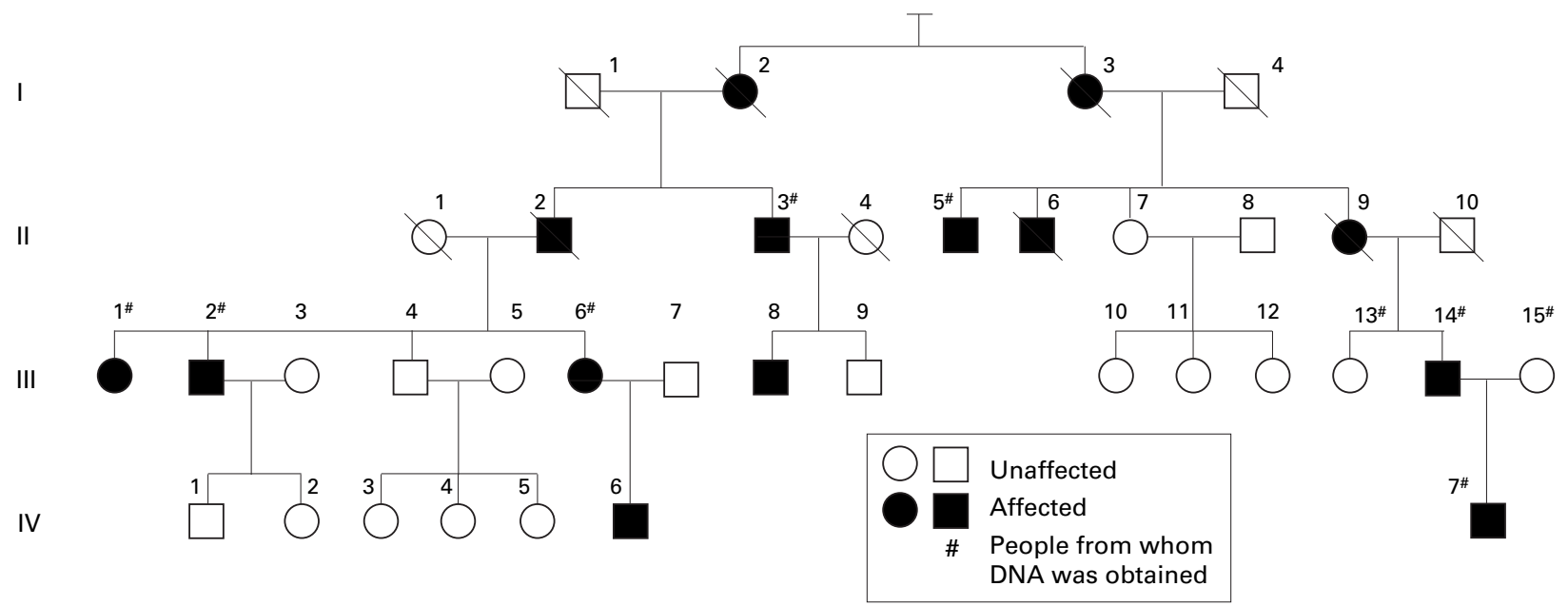

Figure 1 Schematic presentation of the investigated family with hereditary spastic paraplegia. The pedegree shows the disease status of each person. The members III. 14 and IV.7 are carriers of the allelic EAAT2 variant.

of 60 seconds denaturation at $94^{\circ} \mathrm{C}, 60$ seconds primer annealing at $60^{\circ} \mathrm{C}$, and 30 seconds extension at $72^{\circ} \mathrm{C}$. The PCR products were analysed by electrophoresis through a $2 \%$ agarose gel and visualised by ethidium bromide staining.

\section{SINGLE STRAND CONFORMATIONAL ANALYSIS}

(SSCA)

Double stranded PCR product was denatured to single stranded DNA at $95^{\circ} \mathrm{C}$ for three minutes. SSCA was carried out with $2.5 \mu$ of each denatured PCR product mixed with $4 \mu 195 \%$ formamide, $20 \mathrm{mM}$ EDTA, $0.05 \%$ xylene cyanol, and $0.05 \%$ bromphenol blue. For each of the DNA fragments SSCA was performed under four electrophoretic conditionsnamely, on $5 \%$ and $10 \%$ non-denaturing polyacrylamide gels at $11^{\circ} \mathrm{C}$ and $20^{\circ} \mathrm{C}$. The gels were fixed and silver stained according to the protocol of the manufacturer (Qiagen).

SEQUENCING

Sequencing was performed as single strand sequencing of PCR products according to the

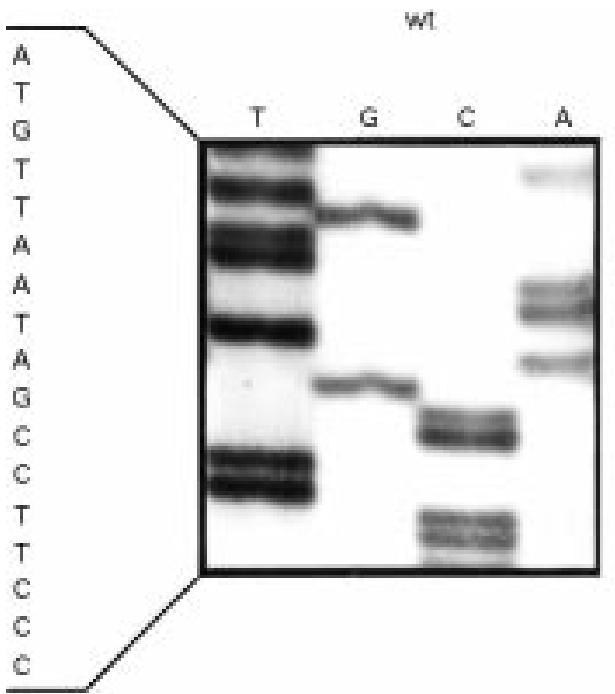

Dynabeads-Streptavidin protocol (Dynal) using Sequenase version 2.0 (USB); PCR products showing a band shift were subcloned (TA Cloning System, Invitrogen), analysed under the same SSCA conditions and sequenced.

\section{Results}

Single strand conformational analysis of the EAAT2 gene did not disclose sequence alterations in the protein coding exons of 55 patients with sporadic ALS. Altered mobility in the SSCA was detected in the second exon of the EAAT2 gene $^{7}$ in two patients with HSP. Direct sequencing of the PCR products showing a band shift disclosed a heterozygous $C$ to $G$ transition at nucleotide position 269 (GenBank O3505) of the EAAT2 transcript (fig 2). The missense mutation replaced the alanine by glycine in position 79 of the putative EAAT2 protein. ${ }^{8}$ The mutation was present in two of seven affected members of our HSP family. We found the sequence variant in one male patient (fig 1, III.14) and his son (fig 1, IV.7). The mutation was not present in five affected

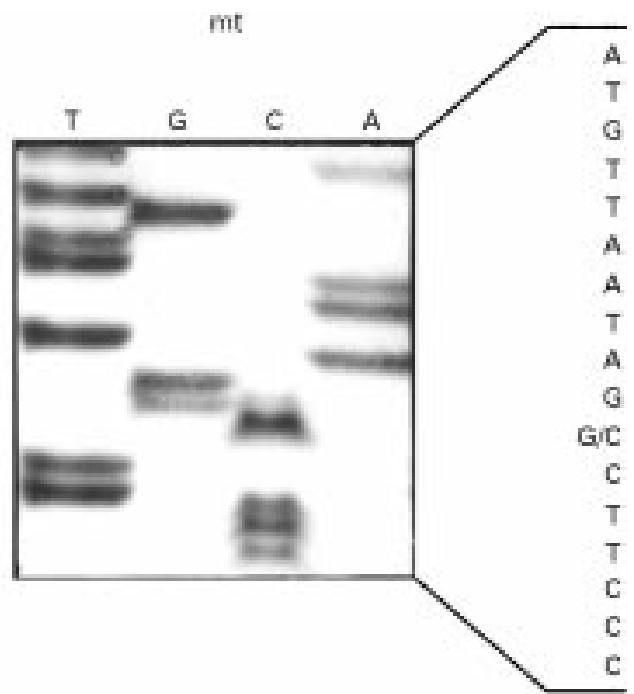

Figure 2 Sequence analysis of the second protein coding exon of the EAAT2 gene. DNA sequence disclosing a $C$ to $G$ change in a patient with HSP (right) compared with the wild type sequence (left). The position of the amino acid transition is indicated. The normal and the mutant nucleotides are present due to the sequencing of both alleles. 
patients and one non-affected member of our HSP family, and DNA samples of 55 patients with sporadic ALS and 50 non-neurological controls, comprising a total of 111 people.

The first patient with HSP carrying the mutation (fig 1, III.14) was a 41 year old man with typical neurological features of HSP including spasticity and increased reflexes of the lower limbs, bilateral Babinski's sign, and sustained ankle tonus. Additional symptoms included decreased vibration sense at the distal lower limbs and mild dysarthria. ${ }^{4}$ The onset of the disorder occurred very early in life as a history of difficulty in learning to walk. Similarily, his 7 year old son (fig 1, IV.7), who also carried the mutation, exhibited early disease onset with a delayed walking ability. The neurological examination disclosed increased reflexes at the lower limbs, spastic resistance to muscle tone examination, and bilateral positive Babinski's sign. Brain MRI demonstrated normal brain images in the two patients carrying the mutation (fig 1, III.14, IV.7) ( MRI data not shown).

\section{Discussion}

Several reports support the hypothesis that deficient glutamate transport may contribute to the pathogenesis of selective motor neuron degeneration. In previous studies we have investigated the EAAT2 transcript in postmortem brain tissue of six patients with ALS. ${ }^{9}$ Here, we report the mutation screening of the EAAT2 gene in a larger group of patients with motor neuron disease using genomic DNA as template. In the present study of 55 patients with sporadic ALS, we did not find abnormalities in the coding exons as analysed by SSCA. Interestingly, we found a A79G missense mutation in the EAAT2 gene of two patients with AD-HSP in the same kindred. In the other patients of the family the mutation was absent. Since there was no cosegregation with the familial disease we conclude that the detected variant is not the cause of disease. However, it is possible that the reported EAAT2 mutation contributes to the pathogenesis of the phenotypically variable AD-HSP. It is unlikely that the allelic variant is a benign polymorphism, because the sequence variant was excluded in 111 subjects, comprising controls and patients with ALS or HSP. Furthermore, database analysis showed that the mutated alanine is conserved in other vertebrates but also among different members of the $\mathrm{Na}^{+} / \mathrm{K}^{+}$-dependent transporter family. ${ }^{8} 10$

In AD-HSP there is a marked intrafamilial variability of age at onset and severity. Possible causes for intrafamilial variability are predisposing genetic and environmental factors. ${ }^{11}$ The allelic variation of EAAT2 in conjunction with the still unknown primary gene defect and possibly other predisposing genetic factors may be a modifying factor for the AD-HSP phenotype. To confirm this hypothesis it will be valuable to study the biophysical properties and the frequency of this mutation in HSP and related diseases.

We thank Professor Astrid Speer, Fachbereich Chemie und Biotechnologie, Technische Fachhochschule Berlin, for providing control DNA samples. We are indepted to Dr Schilling, Department of Radiology, University Hospital Benjamin Franklin, Berlin, and Professor L Harms, Department of Neurology,

1 Nicholls D, Attwell. The release and uptake of excitatory mino acids. Trends Pharmacol Sci 1990;11:462-8.

2 Rothstein JD, Van Kammen M, Levey AI, et al. Selective loss of glial glutamate transporter GLT-1 in amyotrophic lateral sclerosis. Ann Neurol 1995;38:73-84.

3 Spencer PS. Lathyrism. In: Vinken PJ, Bruyn GW, eds. Handbook of clinical neurology. Amsterdam: Elsevier, 1994;21:1-20

4 Sutherland JM. Familial spastic paraplegia. In: Vinken PJ, Bruyn GW, eds. Handbook of clinical neurology. Amsterdam: Elsevier, 1975;22:421-431.

5 Fink JK, Heiman-Patterson T, et al. Hereditary spastic paraplegia: advances in genetic research. Neurology 1996; 46:1507-14.

6 Brooks BR. El Escorial World Federation of Neurology criteria for the diagnosis of amyotrophic lateral sclerosis. $\mathcal{F}$ Neurol Sci 1994;124S: 96-107.

7 Meyer T, Ludolph AC, Morkel M, et al. Genomic organization of the excitatory amino acid transporter gene GLT-1. Neuroreport 1997;8:775-7.

8 Arriza JL, Fairmann WA, Wadiche JI, et al. Functional comparisons of three glutamate transporter subtypes cloned fom human motor cortex. F Neurosci 1994;14:5559-69.

9 Meyer T, Meyer B, Sitte W, et al. The glial glutamate transporter complementary DNA in patients with amyotrophic lateral sclerosis. Ann Neurol 1996;49:456-9.

10 Arriza JL, Kavanaugh MP, Wadiche JI, et al. Cloning and expression of a human neutral amino acid transporter with structural similarity to the glutamate transporter gene family. F Biol Chem 1993;268:15329-32.

11 Dürr A, Davoine CS, Paternotte C, et al. Phenotype of autosomal dominant spastic paraplegia linked to chromosome 2. Brain 1996;119:1487-96. 